\section{IJ§ER}

ISSN: 2149-5939
International Journal of Social Sciences and Education Research

Online, http://dergipark.gov.tr/ijsser

Volume: $1(2), 2015$

\title{
Yüksek şiddetli interval antrenman uygulamalarının etki alanlarının incelenmesi
}

\author{
An analysis on the spheres of influence of high-intensity interval training (HIIT) \\ practices
}

\author{
Mustafa Altınkök ${ }^{1}$
}

\begin{abstract}
Received Date: $01 / 02$ / 2015
Accepted Date: $01 / 04$ / 2015

$\ddot{O} z$

Bu çalışmada, antrenman, egzersiz ve fitnes etkinliklerinde antrenman yöntemlerinden birisi olarak kullanılan, yüksek şiddetli interval antrenman modelinin, insan organizmasının performansı ve bazı parametreleri üzerindeki etkilerini belirlemeye yönelik yapılan araştırma sonuçlarının incelenerek, bu antrenman modelinin etki alanlarını ortaya koymak amaçlanmıştır. Yapılan araştırmalar incelendiğinde her türlü egzersizin insan organizmasındaki kas, kalp-dolaşım ve solunum sistemleri üzerinde olumlu etkilerinin olduğu saptanmıştır. Yapılan araştırmalarla da ortaya konulduğu gibi insan organizması tüm işlevlerini sürdürebilmek ve gerçekleştirmek için gereken enerjiyi aerobik ve anaerobik olmak üzere iki yol ile sağladiğı ortaya konulmuştur. Aerobik yol ile enerji elde edilirken besinlerin (karbonhidrat, yăg ve protein) oksijen ile yakılması söz konusu iken Anaerobik enerji elde etme, besinlerin çok az oksijen ile ya da hiç oksijensiz yakılmasıly oluşmaktadır. Yürüyüş, hızlı yürüyüş, jogging, koşu ve bisiklet aerobik egzersize, hızlı bir şekilde 10-15 basamaklı bir merdiven çıkma ve kısa mesafe koşular anaerobik egzersize örnek olarak verilebilir. Ayrıca 100-200-400 metre koşu, 50-100 metre yüzme, ă̆ırlık kaldırma gibi egzersizler, futbol, basketbol, hentbol ve tenis gibi pek çok spor anaerobik süreçlerin yürütülmesi ile gerçekleştirilir. Anaerobik yol ile enerji yalnızca karbonhidratlardan elde edilir ve şiddetli eforları desteklerken süre yaklaşık 2 dakika ile sınırlıdır. Fakat çoğu egzersiz bu iki sürecin birlikteliğinden oluşmaktadır. Bu süreçlerin enerji elde edilmesine katılım oranları, egzersizin şiddetine ve süresine bă̆ımlı olduğu bilinmektedir. Bu çalı̧̧ma ile farklı araştırmacıların, farklı sürelerde ve modellerde kullandiğı antrenman yöntemlerinden biri olan yüksek şiddetli interval antrenman yöntemi kullanılarak yapılan antrenmanların spor bilimleri ile spor alanlarına katklları ve insan organizmasının performansina etkileri ortaya konulmuştur.
\end{abstract}

Anahtar sözcükler: Antrenman, interval antrenman, yüksek şiddetli interval antrenman

\begin{abstract}
In this study, it was aimed that the results of the research performed for the purpose of determining the effects of high-intensity interval training model used as one of the training methods in training, exercises and fitness activities on the performance of human organism and several parameters be studied and the spheres of influence of this training model be put forward. When the conducted researches were reviewed, it was ascertained that any sort of exercise had positive effects on the muscular, cardiovascular and respiratory systems in the human organism. As is also put forth through the conducted studies, human organism maintains the energy required to be able to sustain and actualize all its functions through two ways as aerobic and anaerobic paths. While nutrients (carbohydrates, fat and protein) are burned through oxygen as the energy is being obtained through the aerobic way, the anaerobic energy, on the other hand, is gained when nutrients are burned with very little amount of energy or even none. Walking, trotting, jogging, running and cycling are some of the examples to aerobic exercise, whereas climbing up 10-15 stairs fast and short distance races can be given as examples to anaerobic exercise. Separately, running 100-200-400 metres, swimming 50-100 meters, exercises like weight lifting, and several sports such as football, basketball, handball and tennis are performed by executing anaerobic processes. The energy through the anaerobic way is gained only from carbohydrates, and the time is limited with approximately 2 minutes while promoting intensive and rigorous efforts. However, most exercises comprise the association of these two processes. It is known that the participation rate (turnout) of these processes in gaining energy depends on the intensity and duration of
\end{abstract}

\footnotetext{
${ }^{1}$ Akdeniz University, Physical Education and Sports High School, ANTALYA/TURKEY, mustafaaltinkok@akde-
} $\underline{\text { niz.edu.tr }}$ 
Altınkök, M. (2015). Yüksek şiddetli interval antrenman uygulamalarının etki alanlarının incelenmesi. International Journal of Social Sciences and Education Research, 1 (2), 463-475.

the exercise. With this study, the contributions of the training performed by using the high-intensity interval training method as one of the training methods used by different researchers in different models and in different periods of time to sports sciences and fields of sports, and also their effects on the performance of human organism have been put forward.

Keywords: Training, interval training, high-intensity interval training

\section{Giriş}

İnsan bedeni özel yetenekleri olan mükemmel bir varlıktır. Merkezi sinir sistemi yaşam dinamizmini kontrol eder. Kalp, yaşam boyu düzenli olarak vücuda kan pompalar. Sürekli egzersizlerle solunum sindirim, boşaltım ve iskelet kas sistemlerinin istenen düzeyde tutulması sağlanır. Uzun süre hareketsiz kalan insan bedeni hareket yeteneğini kaybeder ve sağlık problemleri doğurabilir (Erkan, 1998). Son yıllardaki teknolojik değişiklikler ve ilerlemeler dünyamızda bilim, teknik ve iletişim alanlarında çok hızlı değişim ve gelişim gözlenmesinin yanı sıra bu değişimlerin doğrudan ve dolaylı olarak sportif faaliyetleri ve spor bilimini de etkilemekte, sporcunun sosyal yaşantısı ve performansı üzerinde de etkisini göstermektedir (Günay, 1996, Altın ve Kaya, 2012).

Sportif faaliyetler, özellikle düzenli icra edilen çalışmalar, bireylerin fiziksel gelişimleri ve temel becerileri için önem arz etmektedir. Antrenmanların maksimal çalışma kapasitesini artırdığı bilinen ortak bir gerçektir (Fox, 1988). Antrenmana uyum sağlama, alıştırmaların dizgesel (sistemli) bir biçimde yinelenmesi ile ortaya çıkan değişimlerin toplamıdır (Bompa, 2003). Gençlere uygulanan antrenman metotları daha sonraki spor yaşamının temelini oluşturacağından yetişkinlere uygulanan metotlardan farklı olmak zorundadır. Çocuklar erişkin insanların daha küçük boyutlardaki modelleri değildirler ve kendilerine uygun antrenman yapmalıdırlar (Muratlı, 2007).

Devamlı dayanıklılık egzersizleri, aerobik enerji metabolizmasına dayanan işlevler sırasında performansı artırır. Çalışan iskelet kasında substrat metabolizması değiştirilerek vücudun oksijeni taşıma ve faydalanma yeteneğinin artması sağlanır. Bunun aksine, yüksek şiddetli "sürat koşusu" tipi egzersizlerin ise oksidatif enerji şartlarında ve dayanıklılık kapasitesi üzerinde etkisinin fazla olmadığı düşünülür. Ancak birçok çalışma, en az birkaç hafta yeterince uygulanan yüksek şiddetli interval çalışmaların (HIIT, high intensity interval training) oksijen alımını ve iskelet kaslarındaki enerji üreten mitokondriyal enzimlerin aktivitelerini artırdığını göstermiştir (Gibala, 2007, http, 1). Vücut üzerindeki bu yapısal ve fizyolojik değişimler; antrenman kapsamına, yeğinliğine (şiddet) ve sıklığına bağlı olarak gerçekleştirilen özel bir etkinliğin gerektirdiği yüklemelerin bir sonucudur (Bompa, 2003). Bu doğrultuda spor bilimlerinde ve farklı spor branşlarında performansı arttırmak ve başarıyı kolaylaştırmak için kullanılan en etkili ve önemli antrenman türlerinden birisinin de interval antrenman modeli olduğu bildirilmektedir.

İnterval antrenman, birçok egzersiz serisinin belirli aralıklarla tekrar edilmesidir. İnterval antrenmanın özelliği, çalışma ve dinlenme ya da yüksek ve alçak yüklenme devrelerinin sistemli olarak değişimidir (Revan ve ark., 2008). Buradaki dinlenme tam bir dinlenme değildir. Dolay1sıyla bu antrenmanda hedeflenen dayanıklılık performansı kapasitesini geliştirmek için yorgunluk direncini artırmak gibi görünmektedir (Demiriz, 2013). Fiziksel antrenman sadece yüksek düzeyde yapılan yüklemelerle vücudu uyum sağlamaya zorladığı sürece yararlıdır. Eğer yüklenme vücutta bir değişiklik yaratmak için yeterli değilse, hiçbir biçimde uyum sağlama gerçekleşmez (Bompa, 2003). İnterval (aralıklı) antrenmanın karakteristik özelliği çalışma ve dinlenmenin ya 
Altınkök, M. (2015). An analysis on the spheres of influence of high-intensity interval training (HIIT) practices. International Journal of Social Sciences and Education Research, 1 (2), 463-475.

da yüksek ve alçak yüklenmeli devrenin sistemli olarak değişimidir (Sevim, 2002). İnterval antrenmanlarda temel prensip yüklenmelerde kalp atım sayısı maksimal seviyeye ulaştığında yüklenme durdurularak, kalp atım sayısının tekrarlar arası $120 \mathrm{dk} / \mathrm{at} ı \mathrm{~m}$ setler aras $140 \mathrm{dk} / \mathrm{atım}$ seviyesine indikten sonra tekrar yüklenme yapılır. İnterval antrenmanlarda yüklenmenin şiddeti \% 80-90 dir (Fox ve ark., 1999).

Birçok bilim adamı, teorilerine dayanarak sürat, güç, sürat kuvveti ve patlayıcı kuvvet gelişimindeki rolde interval antrenmana yer verir. Fakat uygulamada tekli yüklemeler arasındaki tam olmayan toparlanmalar (dinlenme) metodu olarak açıklanan interval antrenman metodu daha yakından bir bakışla tamdan ziyade sergilenen kapasitelerdeki toparlanmalar olarak açılkamaktadır. Letzelter (1978) yoğun interval metotlarda patlayıcı kuvveti geliştirmek için 3-50 dakika toparlanmayı tavsiye etmektedir. Buna devamlı (continuous) antrenman metodunun sınırlarında açıç̧a karşı gelinmektedir (http, 2). Astrand ve Rodahl (1987) ise interval antrenmanlarda yüklenme ve dinlenme sürelerinin verimliliğini araştırmışlar ve araştırma sonucunda 1:1 (bire-bir) dinlenme periyodunun uygun olduğundan bahsetmişlerdir (Astrand ve Rodahl, 1987). Eğer yüklenme dayanılmayacak kadar fazlaysa, vücut bundan ya zarar görür ya da aşırı antrenman (sürantrenman) durumu oluşur. Bundan dolayı, doğru antrenman ve yeterli adaptasyonu sağlamış olan sporcular en kısa sürede en fazla gelişim gösterme eğilimindedir (Bompa, 2003).

$\mathrm{Bu}$ çalışmada, her spor branşında kullanılan antrenman yöntemlerinden biri olan, yüksek şiddetli interval antrenman metodunun, uygulama alanlarındaki etkililiği ile sporcuların aerobik ve anaerobik kapasitelerine etkisini ortaya koyan araştırmalardan derleme yapılmıştır.

\section{Yüksek şiddetli interval antrenman tipleri}

Hızlı bir yenilenme sporcunun dinlenme arasını kısaltmasına ve daha yüksek bir yoğunlukta çalışmasına olanak sağlar. Kısa dinlenme aralarının bir sonucu olarak tekrar sayısı arttırılabilir böylece antrenman kapsamında artış yapılması kolaylaşır. Yüksek bir aerobik kapasite ile desteklenmiş olan hızlı yenilenme bir hareketin çok sayıda tekrarının gerekli olduğu sporlarda ya da dinlenme aralarının gerekli olduğu takım sporlarında önemlidir (Bompa, 2003). Sporla ilgilenenlerin amacı kişinin beden ve ruh sağlığını geliştirmek kendine güven kazanmasını sağlamak ve üst düzey performansı elde etmektir (Bilge, 2000). Her geçen gün düzenli yapılan bedensel egzersizler, sağlık için önemi daha belirginleşmektedir. Egzersizleri; kasların, kemiklerin, eklemlerin, kalp-damar sistemi ve fonksiyonlarının en uygun şekilde çalışmasını sağlamaktadır. Dayanıklılık sporları (Uzun mesafe koşuları, bisiklet, uzun mesafe yüzme vb.) yapanlarda kroner arter hastalığı hipertansiyon ve şeker hastalığı daha az görülür (Akgün, 1973).

Dayanıklılık antrenmanlarının vücut kompozisyonu üzerine etkileri incelendiğinde uygulanan antrenmanlar sonucunda toplam vücut ağırlığ 1 , vücut yağ yüzdesi, vücut kitle indeksi ve tüm deri kıvrım kalınlığı ölçümlerinde önemli azalmalar, vücut yoğunluğu ve yağsız vücut kitlesinde ise önemli artışlar olduğu tespit edilmiştir (Gökdemir ve ark., 2007, Patlar ve ark., 2003, Trapp ve ark., 2008). Dayanıklılık gelişiminde, aralıklı antrenman metodu ile devamlı antrenman metodu arasındaki sınır çizgisini belirlemek oldukça zordur. Bu fark, aralıklı antrenmandaki yüklenmenin süresine göre belirlenir. Birçok araştırma kısa interval antrenmanı 15 saniye-2 dakika, orta interval antrenmanı 2-8 dakika ve uzun interval antrenmanı da 8-15 dakika olarak belirlemiştir. Bu belirlemede aralıklı antrenmanda sergilenen efor ve toparlanma arasındaki sistematik değişimlere dayalı uyarının çeşidi göz ardı edilmiştir (http, 2). İnterval antrenmanlarda temel kural kalp atım sayısı 180-200'e ulaştığında çalışmanın durdurulması; 120-130'a düşünce çalışmaya devam edilmesidir. Dikkat edilmesi 
Altınkök, M. (2015). Yüksek şiddetli interval antrenman uygulamalarının etki alanlarının incelenmesi. International Journal of Social Sciences and Education Research, 1 (2), 463-475.

gereken genel ilkeler çalışmanın süresi, kapsamı, şiddeti (yoğunluğu) ve dinlenme olarak sıralanabilir (http, 3).

Peter Coe Tipi Yüksek Şiddetli İnterval Antrenman: Atletizm antrenörü Peter Coe tarafindan 1970'lerde uygulanan bir yöntemdir. Bu yönteme göre seanslar 200 metre hızlı koşu ve her 200 metre koşu aralığında 30 saniye dinlenme sürecinden oluşur (Coe, 2013).

Tabata Tipi Yüksek Şiddetli İnterval Antrenman: Izumi Tabata ve diğer araştırmacılar tarafindan 1996 yılında yapılan bir çalışmaya dayanan yüksek şiddetli interval antrenman tipidir. Olimpik sürat patencileri tarafından uygulanmıştır. Yönteme göre 20 saniye ultra-yoğun egzersiz (yaklaşık \%170 VO2max) ve bunu takiben 10 saniye dinleme süreci gerçekleştirilir. Devamlı olarak 4 dakika boyunca (8 döngü) gerçekleştirilir (Tabata, 1996).

Gibala Tipi Yüksek Şiddetli İnterval Antrenman: Martin Gibala ve takımı, Kanada'da Mc Master Üniversitesi'nde yıllardır yüksek şiddetli interval antrenman üzerine araştırmalar yapmaktadır. 2009 çalışmalarında kullanılan yöntemde, 3 dakika 1sınma, ardından 60 saniye yoğun antrenman (\%95 VO2max) ve bunu takiben 75 saniye dinlenme süreci uygulamışlardır. Uygulama tekrarlanan 8-12 döngüden oluşmaktadır (Little, 2009).

Timmon Tipi Yüksek Şiddetli İnterval Antrenman: Jamie Timmons, BBC kanalında Şubat, 2012'de katıldığ 1 Horizon programında, Michael J. Mosley'e uygulattığ 1 yöntemdir; egzersiz bisikletinde 2 dakika hafif pedal ardından 20 saniye en yüksek eforla hızlanma basamağından oluşmaktadır. $\mathrm{Bu}$ yöntem ısınma ve dinlenme basamakları ile birlikte haftada 3 kez 3 dakika uygulanmıştır. Sağlığa olan ölçülebilir faydaları arasında insülin hassasiyetinde kayda değer gelişme rapor edilmiştir (http, $5)$.

Reilly, aerobik olarak iyi antrene edilmiş oyuncuların, aerobik güç ve kapasitesi daha zayıf oyunculara oranla, oyunun sonlarına kadar kendi çalışma şiddetini koruyabilme özelliklerinin daha yüksek olduğunu belirtmiştir (Reilly, 2000). Helgerud, aerobik güç ve anaerobik eşik performanslarında meydana gelen artışın miktarının haftada en az iki dayanıklılık antrenmanının uygulanmasına bağlı olduğunu belirtmektedir (Helgerud ve ark., 2001).

Futbol'un ve diğer spor dallarının kapsamında bulunan sıçrama, tutma, dönme, yüksek hızda ki koşular ve sprint gibi çok şiddetli olarak yapılan aktivitelerden dolayı, aralıklı sporların yüksek fiziksel isteklere sahip oldukları bilinmektedir (Krustrup, 2003). Oyuncuların uzun bir zaman dönemi içinde yüksek bir seviyede oynayabilmek için jogging ve yürüme gibi düşük yoğunluktaki aktiviteler esnasında toparlanma kapasiteleri ile sprint ve koşu gibi yüksek yoğunluktaki aktiviteleri yapabilmek için çok iyi geliştirilmiş bir kapasiteye ihtiyaçları bulunmaktadır (Lemmink, 2004). Örneğin, Futbol maçı sırasında ortalama egzersiz şiddeti; anaerobik eşiğe yakın ya da maksimum kalp atım hızının \%80-90’ı civarında olduğu ifade edilmektedir. Egzersiz şiddetinin artması kanda ve kasta laktik asit birikmesi ile sonuçlanmaktadır. Bu durum da sporcunun yorulmasına ve performansının düşmesine neden olmaktadır. Oyun içerisindeki kısa süreli şiddetli hareketlerin aynı kalitede tekrarlanabilmesi dayanıklılık kapasitelerinin gelişmiş olması ile yakından ilişkilidir ve hareketler sırasında tükenen anaerobik enerji kaynaklarının aerobik enerji kaynakları kullanılarak yenilenmesine bağlıdır. Dolayısıyla yüksek şiddetli interval çalışmaların kas metabolizmasını geliştirmesi futbolcular için önemli bir durumdur. Maçın doğası gereği başlamadurma, koşma ve zıplama için kasların aerobik ve anaerobik enerji sistemlerine yüksek gereksinimi vardır. Yüksek şiddetli interval çalışmalarda da bu iki enerji sistemi baskı altındadır. Bu 
Altınkök, M. (2015). An analysis on the spheres of influence of high-intensity interval training (HIIT) practices.

International Journal of Social Sciences and Education Research, 1 (2), 463-475.

nedenle bu egzersizler, oyun içinde futbolcuların daha verimli şekilde pozisyon değiş̧irmelerini sağlar (http, 4, Köklü ve ark., 2009).

\section{Yüksek şiddetli interval antrenman uygulamaları}

Çevik ve arkadaşlarının (1996)'da Farklı aerobik nitelikli antrenmanların serum enzimler, serum elektrolitler, üre, kreatin, total protein, fosfor ve ürik asit üzerindeki etkileri ve ilişki düzeylerinin belirlenmesi konulu çalışmasında, sekiz hafta süreyle uygulanan devamlı ve aralı koşu programlarının sonucunda, kreatin ve üre düzeyleri için A.Ö ve A.S değerler arasında anlamlı bir fark olmadığını tespit etmişlerdir.

Koç ve arkadaşlarının (2007)'de Devamlı ve aralı (interval) koşu programlarının plazma üre ve kreatin düzeyleri üzerine etkisini belirlemek amacı ile yaptığı çalışmada, sekiz hafta süreyle uygulanan devamlı ve aralı koşu programlarının sonucunda, üre ve kreatin düzeylerinde değişmelerin olduğu, ancak bu değişikliklerin istatistiksel olarak anlamlı olmadığ tespit edilmiştir.

Kargotich ve arkadaşları (2007)'de altı haftalık dayanıklılık antrenmanın üre düzeyi üzerine etkisini belirlemek amacı ile yapmış oldukları çalışmada, antrenman programına katılan deneklerin üre düzeyinde 2. ve 4. haftalarda artışların olduğunu, ancak bu artışların istatistiksel olarak anlamlı olmadığını belirtmişlerdir.

Lewine ve Gunderson (1992)'de, 19 uzun mesafeci üzerinde yüksek irtifa ve deniz seviyesinde aerobik performansın değerlendirmesi için yaptıkları çalışmada, 9 deneğe 2500-3000 metrede, 10 deneğe ise deniz seviyesinde, 4 hafta süre ile interval antrenman yaptırmışlardır. Denekleri, antrenman başlamadan önce ve bittikten iki gün sonra, 150 metre deniz seviyesinde teste tabi tutulmuşlardır. Maximal treadmil koşusunda, maksimal kalp atım sayısının yüksek irtifada çalışan grubun, 175 atım/dk.' dan 171 atım/dk.'ya gerilediği, deniz seviyesinde çalışan grubun ise 171 atım/dk.' dan 160 atım/dk.' ya gerilediği gözlemlenmiştir.

Savaş (2000)'de deniz seviyesi ile yükseltide uygulanan dayanıklılık antrenmanlarının bazı fizyolojik parametrelere olan etkilerinin tespiti ve üç hafta sonra tekrarlanan ölçüm değerleri ile karşılaştırılmasını araştırdığı çalışmasında, 22 deneğin yükseltiye çıkmadan önce aldığ 1 ilk öl-

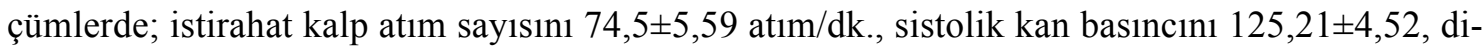
astolik kan basıncınıda $80,08 \pm 2,09$ olan değerlerini 8 hafta sonra yükseltiden dönüldüğünde, istirahat kalp atım sayısını 73,0 3,72 atım/dk, sistolik kan basıcı için 123,42 $\pm 3,9$, diastolik kan basıncı için $79,79 \pm 1,72$ olarak tespit etmiştir.

Baydil (2005)'te lise düzeyindeki sedanter erkekler üzerinde, yüksek irtifada uygulanan yoğun interval antrenman programının, meydana getirdiği istirahat kalp atım sayıları, sistolik-diastolik kan basınçları ve hemoglobin konsantrasyonları gibi bazı fizyolojik parametreleri araştırdığı çalışmada, aldığı ölçümler sonucunda yüksek irtifada yoğun interval antrenman programı uygulayan grubun sonuçlarını diğer gruba göre anlamlı bulmuştur.

Taş ve Zorba (2010)' da düzenli olarak egzersiz yapmayan, gönüllü 30 erkek öğrencinin katıldığı, sıcak ortamda yapılan farklı antrenman metotlarının glutatyon (gsh) ve malondialdehit (mda) düzeylerine etkisinin karşılaştırılmasının yapıldığ çalışmada, çalışma grubunu sürekli koşular $(\mathrm{n}=15)$ ve interval koşular $(\mathrm{n}=15)$ olmak üzere 2 gruba ayırmıştır. Antrenman gruplarına, 8 hafta boyunca, haftada 3 gün antrenman programı uygulanmış ve deneklerin her birinden, çalışma öncesi ve 8 haftalık çalışma programı sonrasında kan örnekleri alınmış. Antrenman metotlarının önson test sonuçlarına göre GSH ve MDA değerleri karşılaştırılmış ve gruplar arasında istatistiksel 
Altınkök, M. (2015). Yüksek şiddetli interval antrenman uygulamalarının etki alanlarının incelenmesi. International Journal of Social Sciences and Education Research, 1 (2), 463-475.

olarak anlamlı bir farklılık görülmemiştir. Sıcak ortamda yapılan interval ve sürekli koşu antrenmanlarından, sürekli koşular grubunda istatistiksel bir artış olmamasına rağmen MDA düzeyinde görülen artıştan dolayı oksidatif stresin daha baskın olduğunu bildirmişlerdir.

Günay ve arkadaşlarının (1998)'de 20-21 yaş ortalamasına sahip 30 üniversite öğrencisi üzerinde yaptıkları İki farklı tipteki interval antrenman programlarının aerobik, anaerobik güç, vücut kompozisyonu, solunum fonksiyonları, kan lipitleri, kan basıncı ve istirahat nabzı üzerine etkileri konulu çalışmada, $1200 \mathrm{~m}$ x 4 seri yapan grup ta vücut ağırlığı antrenman öncesi 67.48 , antrenman sonras1 67.00, vücut yağ yüzdesi antrenman öncesi 8.92, antrenman sonras1 7.27 bulunurken 400 m x 12 seri yapan grupta ise vücut ağırlığ 1 antrenman öncesi 73.42 , antrenman sonrası 74.18 , vücut yağ yüzdesi antrenman öncesi 8.69 antrenman sonrası 7.54, olarak tespit edilmiştir.

Mc Manus (1993)'te 9,6 yaş ortalamasına sahip kız öğrenciler üzerinde yapmış olduğu araştırmada, sekiz haftalık sürekli ve interval antrenman uygulaması sonucunda MaksVO2 değerlerindeki artışın sürekli koşu yapan deneklerde anlamlı düzeyde yüksek olduğunu bulmuştur. Williams (1993)'te 9,6 yaş ortalamasına sahip kız öğrenciler üzerinde yapmış olduğu süreli ve araklı interval antrenmanların ergin kızların anaerobik performansına etkileri konulu çalışmada, interval sprint antrenmanlarının anaerobik performansı arttırdığı bildirilmiştir.

Yüksel ve arkadaşlarının (2007)'de yaptığ1, sürekli ve interval antrenman programlarının üniversite öğrencilerinin aerobik ve anaerobik gücüne etkisi konulu çalışmada, düzenli olarak sekiz hafta süreyle haftada üç gün uygulanan sürekli ve interval antrenman uygulamalarında, sürekli koşular metodunun vücut ağırlığ kisinin olduğu, interval antrenmanların ise vücut ağırlığı, vücut yağ yüzdesi ve anaerobik güç değerleri üzerine etkisinin olmadığı sonucuna varılmıştır.

Koç ve arkadaşları (2007)'de 8 hafta süreyle uygulanan her iki koşu programlarının da vücut ağırlığı ve VKİ değerlerini azalttığını belirtmişlerdir. Ribeiro Braga ve arkadaşlarının (2004)'te Obezlerde yaptığı çalışmada, 12 hafta süre ile haftada 5 gün, günde 45 dakika uyguladığı sürekli ve interval yüzme egzersizlerinin, kilo kaybında etkili olduğunu tespit edilmiştir. Chilibeck ve arkadaşlarının (1998)'de yüksek yoğunluklu interval antrenmanların yağ asidi oksidasyonunu artırmada sürekli submaksimal antrenmanlara göre daha etkili olduğunu belirtmişlerdir.

Helgerud ve arkadaşları (2007)'de yapmış oldukları çalışmada, sadece \%70 maksimal kalp atım sayısı (maks KAS) ile 45 dakika sürekli koşu yapan grupta vücut ağırlığı ortalamalarında anlamlı düzeyde azalma gözlerken, maksVO2 değerlerinde ise laktat eşiğinde \%85 maks KAS ile 24-25 dakika sürekli koşu ve \%90-95 maks KAS ile interval koşu gruplarında anlamlı düzeyde artışlar tespit etmişlerdir.

Berger ve arkadaşlarının (2006)'da 6 hafta süreyle haftada 3-4 gün uygulanan sürekli ve yüksek yoğunluklu interval antrenmanlarının maksVO2 değerlerinde kontrol grubuna göre anlamlı düzeyde artışlara neden olduğu, vücut ağırlı̆̆ında ise grupların hiçbirinde anlamlı değişimin olmadığ ve her iki antrenman grubundaki değişimlerin benzer olduğu belirtilmiştir.

Overend ve arkadaşlarının (1992)'de 10 hafta süreyle yapılan yüksek ve düşük yoğunluklu interval antrenmanların, maksVO2 değerlerinde sürekli antrenmanlarla benzer faydalar sağladığını ve gruplar arasında fark olmadığını belirtmişlerdir. Morris ve arkadaşlarının (2002)'de yaptıkları çalışmada \%70-75 maksVO2 ile 10 hafta süreyle yapılan sürekli ve interval antrenmanlar sonunda her iki antrenman grubunda da maksVO2 değerlerinde benzer ve anlamlı artışlar tespit edilmiştir. 
Altınkök, M. (2015). An analysis on the spheres of influence of high-intensity interval training (HIIT) practices.

International Journal of Social Sciences and Education Research, 1 (2), 463-475.

Mc Manus ve arkadaşlarının (2005)'te yaptığ 1 sürekli ve aralıklı interval antrenmanın ilkokul çocukların aerobik kapasitesine etkisini incelediği çalışmada, yetişkinlerde olduğu gibi çocuklarda da sürekli ve yüksek yoğunluklu interval antrenmanların maksVO2 değerlerinde, kontrol grubuna göre anlamlı düzeyde artışlarla sonuçlanmıştır. Koç ve Tamer (2008)'de yaptığı, aerobik ve anaerobik antrenman programlarının lipoprotein düzeyleri üzerine etkisi konulu çalışmada, şiddeti \% 80 devamlı koşular ile şiddeti \% 90 interval koşuların LDL düzeyinde azalma ve HDL düzeyinde ise artma sağlandığını tespit etmiş.

Günay ve arkadaşlarının (2000)'de yaptığı, iki farklı tipteki interval antrenman programlarının bazı fizyolojik parametreler üzerine etkisi konulu çalışmada, birinci tip yüksek yoğunluklu interval antrenmanlarının ikinci tip yüksek yoğunluklu interval antrenmanlarına göre anlamlı düzeyde artışlara neden olduğu ve her iki antrenman grubundaki değişimlerin benzer olduğu belirtilmiştir.

Revan ve arkadaşlarının (2008)'de sürekli ve interval koşu antrenmanlarının vücut kompozisyonu ve aerobik kapasite üzerine etkilerini araştırmak amacıyla yaptığı araştırmada, çalışma grupları sürekli koşular $(n=13)$, interval koşular $(n=12)$ ve kontrol $(n=13)$ olmak üzere 3 gruptan oluşmuştur. Antrenman gruplarına, 8 hafta boyunca, haftada 3 gün antrenman programı uygulanırken, kontrol grubuna herhangi bir program uygulanmamıştır. Ölçüm sonuçlarının karşılaştırılması sonucu, vücut ağırlığı ve vücut kitle indeksi değerlerinde sadece sürekli koşular grubunda, vücut yağ yüzdesi, toplam skinfold ve maksVO2 değerlerinde ise, sürekli koşu ve interval koşu gruplarında anlamlı farklar bulunmuştur.

Halson ve arkadaşlarının (2003)'te yaptıkları çalışmada, 2 hafta normal antrenmanın ardından, 4 hafta intensiv antrenman uyguladıkları araştırma sonucunda, eritrosit ve hemoglobin parametrelerinde birinci, ikinci ve üçüncü haftalarda ritmik ve anlamsız düşüşler bulurlarken, dört, beş ve altıncı haftalarda düzenli ve anlamlı artışlar bulmuşlardır.Erol ve arkadaşları (1997)'de yaptıkları çalışmada, 13-14 yaş erkek basketbolculara uyguladıkları 10 haftalık ekstensiv interval metodu antrenman sonucunda vücut yağ yüzdesi ortalamalarında \%13,56 azalma, yağsız vücut ağırlığ 1 ortalamasında ise $\% 3,84$ artış olduğunu ortaya koymuşlardır.

Demiriz ve arkadaşlarının (2015)'de farklı dinlenme aralıklarında ve aynı şiddette yapılan anaerobik ekstensive ve intensive interval antrenmanın aerobic ve anaerobic kapasite ve kan parametreleri üzerindeki etkisini tespit etmek için yaptıkları çalışmada, birinci gruba, intensiv interval antrenman (İ̈A grubu, $\mathrm{N}=10$ ) ve ikinci gruba, ekstensiv interval antrenman (EİA grubu, $\mathrm{N}=10$ ) programı uygulanarak, antrenman programı öncesi ve sonrası olarak kan ve fiziksel testler uygulanmış. Ekstensive interval antrenmanın antrenörlerce VO2max ve anaerobik eşik seviyelerini artırmak için yapılabileceği sonucuna ulaşmışlardır.

$\mathrm{Bu}$ çalışma sonuçlarına ilaveten interval metodun sürekli egzersiz metoduna göre aerobik uygunluğu daha fazla artırdığını ortaya koyan çalışma sonuçları da bulunmaktadır (Ribeiro Braga ve ark., 2004, Daussin ve ark., 2007, Gorostiaga ve ark., 1991).

\section{Sonuç}

Devamlı dayanıklılık egzersizleri, aerobik enerji metabolizmasına dayanan işlevler sırasında performansı artırırken, yüksek şiddetli interval çalışmalar, aerobik ve anaerobik enerji sistemlerinin daha etkili kullanılabilmesini sağlamaktadır. Yapılan çalışmalarda bu antrenmanların oksijen alımını ve iskelet kaslarındaki enerji üreten mitokondriyal enzimlerin aktivitelerini artırdığ 1 
Altınkök, M. (2015). Yüksek şiddetli interval antrenman uygulamalarının etki alanlarının incelenmesi. International Journal of Social Sciences and Education Research, 1 (2), 463-475.

belirtilmiştir. Bu sayede tükenen anaerobik enerji kaynaklarının aerobik enerji kaynakları kullanılarak yenilenmesi ile dayanıklılık kapasitesinin artması sağlanmaktadır. Futbol, voleybol, hentbol ve basketbol gibi yüklenme yoğunluğunun maç esnasında değişken olduğu sporlar için yüksek şiddetli interval antrenmanlar dayanıklılık gelişimi açısından önemlidir.

Gibala ve diğerleri 2006'da yaptıkları çalışmada, 2.5 saat interval antrenmanın 10,5 saat devamlı antrenman ile aynı seviyede biyokimyasal kas değişikliği sağladığını göstermişlerdir. Driller ve diğerlerinin 2009 çalışmasının sonucuna göre, 4 hafta yüksek şiddetli interval antrenmanla çalışan kürek sporcularında 2000 metre kürek sporunda 8.2 saniye gelişme görülmüş̧ür. Bu sonuç 7 antrenman sonucunda \%2 belirgin gelişime eşdeğerdir. Ayrıca Boutcher (2011) yüksek şiddetli interval antrenmanın insülin direncini kayda değer seviyede düşürdüğünü ve iskelet kaslarında da adaptasyonlara sebep olduğunu; bunun sonucunda iskelet kası yağ oksidasyonunda gelişme ve glikoz toleransında artış görüldügünü belirtmiştir. Ayrıca insülin direncinde gösterdiği etki, tip 2 diyabetin önlenmesine de yardımcı olmaktadır.

Overend ve arkadaşları, 10 hafta süreyle yapılan yüksek ve düşük yoğunluklu interval antrenmanların, maksVO2 değerlerinde sürekli antrenmanlarla benzer faydalar sağladığını ve gruplar arasında fark olmadığını belirtmişlerdir (Overend ve ark., 1992). Yine benzer bir çalışmada \% 7075 maksVO2 ile 10 hafta süreyle yapılan sürekli ve interval antrenmanlar sonunda her iki antrenman grubunda da maksVO2 değerlerinde benzer ve anlamlı artışlar tespit edilmiştir (Morris ve ark., 2002).

Yapılan diğer çalışmara bakıldığında interval aerobik egzersizlerin maksVO2 değerlerini benzer biçimde önemli düzeyde artırdığı söylenebilir. Ayrıca interval antrenman metodun sürekli egzersiz metoduna göre aerobik uygunluğu daha fazla artırdığını gösteren çalışma sonuçları da mevcuttur (Ribeiro ve ark., 2004, Daussin ve ark., 2007, Gorostiaga ve ark., 1991).

Sonuç olarak, yapılan çalışmalar yüksek şiddetli interval antrenman uygulamalarının başarılı sonuçlar verdiğini göstermektedir. Bunun yanı sıra, uygulanan antrenman programlarının tipi, süresi ve şiddeti, deneklerin türü, program öncesi ve sonrası ölçümlerin yapıldığı süreler, kullanılan yöntemlerin farklı olması ve araştırmanın farklı ortamda yapılması gibi nedenlerden dolayı, sonuçların farklı düzeylerde etkilendiği görülmektedir.

\section{Kaynakça}

Akgün, N. (1973). Egzersiz fizyolojisi. 6. Bask1, I. Cilt, İzmir.

Altın, M., Kaya, Y. (2012). 14-16 yaş grubu futbolcularda intensiv interval antrenman metodunun aerobik ve anaerobik güce etkisi. Selçuk Üniversitesi Beden Eğitimi ve Spor Bilim Dergisi, 14 (2): 253256.

Astrand, P.O and Rodahl, K. (1987). Textbook of work physiology. Mc Graw Hill, Singapore.

Baydil, B. (2005). Lise düzeyindeki sedanter erkeklerde yüksek irtifada uygulanan yoğun interval antrenman programının bazı fizyolojik parametrelere etkisi. Kastamonu Eğitim Dergisi, Mart, Cilt:13, No:1, 299-310.

Berger, N.J., Tolfrey, K., Williams, A.G., Jones, A.M. (2006). Influence of continuous and interval training on oxygen uptake on- kinetics. Medicine Science in Sports and Exercise, 38 (3), 504-512.

Bilge, M. (2000). Türk bayan hentbol milli takımı oyuncularının somatotip profilleri ve yabancı ülke sporcuları ile karşılaştırılması. Spor Araştırmaları Dergisi, 4. Cilt, Ankara. 
Altınkök, M. (2015). An analysis on the spheres of influence of high-intensity interval training (HIIT) practices. International Journal of Social Sciences and Education Research, 1 (2), 463-475.

Bompa, T.O. (2003). Dönemleme antrenman kuramı ve yöntemi. 2. Bask1, Ankara, Dumat Ofset, 365-372.

Boutcher, S.H., (2011). High-intensity intermittent exercise and fat loss. Journal of Obesity 2011:868305.

Chilibeck, P.D., Bell, G.J., Farrar, R.P., Martin, T.P. (1998). Higher mitochondrial fatty acid oxidation following intermittent versus continuous endurance exercise training. Can J Physiol Pharmacol, 76(9), 891-894.

Coe, S., (2013). Running my life. Hodder. pp. 38-39.

Çevik, C., Günay, M., Tamer, K., Sezen, M., Onay, M. (1996). Farklı aerobik nitelikli antrenmanların serum enzimler, serum elektrolitler, üre, kreatin, total protein, fosfor ve ürik asit üzerindeki etkileri ve ilişki düzeylerinin belirlenmesi. Gazi Üniversitesi. Beden Eğitimi ve Spor Bilimleri Dergisi, 1 (2):37.

Daussin, F.N., Ponsot, E., Dufour, S.P., Lonsdorfer-Wolf, E., Doutreleau, S., Geny, B., Piquard, F., Richard, R. (2007). Improvement of vo2 max; by cardiac output and oxygen extraction adaptation during intermittent versus continuous endurance training. Eur J Appl Physiol, 101, 377-83.

Demiriz, M. (2013). Farkl dinlenme aralıklarında yapılan anaerobik interval antrenmanın, aerobik kapasite, anaerobik eşik ve kan parametrelerine etkilerinin karşılaştırılması. Yüksek Lisans Tezi.

Demiriz, M., Erdemir, İ., Kayhan, R.F. (2015). Farklı dinlenme aralıklarında yapılan anaerobik interval antrenmanın, aerobik kapasite, anaerobik eşik ve kan parametreleri üzerine etkileri. Uluslararası Spor, Egzersiz ve Antrenman Bilimi Dergisi, Cilt 1, Say1 1, 1-8, DOI: 10.15390/EB.2015.XXX.

Driller, M., Fell, J., Gregory, J., Shing, C., Williams, A., (2009). The effects of high-intensity interval training in well-trained rowers. International Journal of Sports Physiology and Performance 4:1.

Erkan, N. (1998). Yaşam boyu spor. Ankara.

Erol, E., Tamer, K., Sevim, Y., Cicioğlu, İ., Çimen, O. (1997). Yaygın interval metot ile uygulanan dayanıklılık çalışmalarının 13-14 yaş grubu erkek basketbolcuların aerobik-anaerobik güç ve bazı fiziksel parametreler üzerine etkilerinin incelenmesi. Performans Dergisi, 3(1): 7-15.

Fox, E.L. (1988). The physiological basis of physical education and athletics. (Çev. M.Cerit), Bağırgan Yayımevi, Ankara.

Fox, E.L., Bowers, R.W., Foss, M.L. (1999). Beden ĕgitimi ve sporun fizyolojik temelleri. (Çeviri:Cerit M.), Bağırgan Yayınevi, Ankara.

Gibala, M.J., (2007). High-intensity interval training: new insights. Sports Science Exchange, Volume 20.

Gibala, M.J., Jonathan, P., Little, M.E., Geoffrey, P., Wilkin, K.A., Burgomaster, A.S., Sandeep, Raha and Mark A.T., (2006). Short-term sprint interval versus traditional endurance training: similar initial adaptations in human skeletal muscle and exercise performance. Journal of Physiology 575 (3): 901-911.

Gorostiaga, E.M., Walter, C.B., Foster, C., Hickson, R.C. (1991). Uniqueness of interval and continuous training at the same maintained exercise intensity. Eur J Appl Physiol Occup Physiol, 63 (2), 1017.

Gorostiaga, E.M., Walter, C.B., Foster, C., Hickson, R.C. (1991). Uniqueness of interval and continuous training at the same maintained exercise intensity. Eur J Appl Physiol Occup Physiol, 63(2), 1017.

Gökdemir, K., Koç, H., Yüksel, O. (2007). Aerobik antrenman programının üniversite örencilerinin bazı solunum ve dolaşım parametreleri ile vücut yağ oranı üzerine etkisi. SDÜ Egzersiz, 1:1.

Günay, M. (1996). Futbol antrenmanının bilimsel temelleri. Gazi Yayınevi, Ankara. 
Altınkök, M. (2015). Yüksek şiddetli interval antrenman uygulamalarının etki alanlarının incelenmesi. International Journal of Social Sciences and Education Research, 1 (2), 463-475.

Günay, M., Cicioğlu, İ., Savaş, S. (1998). İki farklı tipteki interval antrenman programlarının aerobik, anaerobik güç, vücut kompozisyonu, solunum fonksiyonları, kan lipitleri, kan basınc1 ve istirahat nabzı üzerine etkileri. Kastamonu Eğitim Fakültesi Dergisi, 4 (6), 163.

Günay, M., Tamer, K., Cicioğlu, İ., Çevik, C. (2000). İki farklı tipteki interval antrenman programlarının bazı fizyolojik parametreler üzerine etkisi, Ege Üniversitesi Spor Hekimliği Dergisi, 35 (4): 143.

Halson, S.L., Lnacaster, G.I., Jeukendrup, A.E. \& Gleeson, M. (2003). Immunological responses to overreaching in cyclists. Medicine Science in Sports and Exercise, 854-86.

Helgerud, J., Engen, L.C., Wisloff, U., Hoff, J. (2001). Aerobic endurance training improves soccer performance. Medicine and Science in Sports Exercise, 33:1925-1931.

Helgerud, J., Hoydal, K., Wang, E., Karlsen, T., Berg, P., Bjerkaas, M., Simonsen, T., Helgesen, C., Hjorth, N., Bach, R., Hoff, J. (2007). Aerobic high-intensity intervals improve vo2 max more than moderate training. Medicine Science in Sports and Exercise, 39 (4), 65-71.

http 1. http://www.simplyshredded.com/cardio-for-fat-loss-high-intensity-interval-training-cardio-vs-low-intensity-steady-state-cardio.html (12.05.2014).

http 2. http://www.atletik.org/ABTD-makaleler/makale-abtd0345-sayi47-sayfa5-antrenman\%20metodlari.htm (09.05.2014).

http 3. http://www.trabzonbasket.com/?pnum=114\&pt=Dayan $\% \mathrm{C} 4 \% \mathrm{~B} 1 \mathrm{kl} \% \mathrm{C} 4 \% \mathrm{~B} 11 \% \mathrm{C} 4 \% \mathrm{~B} 1 \mathrm{k} \% 20 \mathrm{Ant}-$ renman\%20Metodlar\%C4\%B1 (13.05.2014).

http 4. http://www.scienceofsocceronline.com/2013/11/the-advantages-of-high- intensity.html (10.05.2014).

http 5. http://en.wikipedia.org/wiki/High-intensity_interval_training (04.05.2015).

Kargotich, S., Keast, D., Goodman, C., Bhagat, C.I., Joske, D.J., Dawson, B., Morton A.R. (2007). Monitoring 6 weeks of progressive endurance training. Int J Sports Med. Mar, 28 (3): 211-216.

Koç, H. ve Tamer, K. (2008). Aerobik ve anaerobik antrenman programlarının lipoprotein düzeyleri üzerine etkisi. Să̆lık Bilimleri Dergisi (Journal of Health Sciences), 17(3), 137-143.

Koç, H., Tamer, K., Çoksevim, B., (2007). Devamlı ve aralı (interval) koşu programlarının plazma üre ve kreatin düzeyleri üzerine etkisi. Sağlık Bilimleri Dergisi, 16(1), 17-22.

Koç. H., Tamer, K., Çoksevim, B. (2007). Devamlı ve aralı (interval) koşu programlarının plazma üre ve kreatin düzeyleri üzerine etkisi. Sağllk Bilimleri Dergisi (Journal of Health Sciences) 16(1) 1722 .

Köklü Y., Özkan A., Ersöz G., (2009). Futbolda dayanıklılık performansının değerlendirilmesi ve geliştirilmesi. BESBD 2009;4 (3).

Krustrup, P. (2003). The yo-yo intermittent recovery test: physiological response, reliability, and validity, Medicine and Science in Sports Exercise, 35(4), 697-705.

Lemmink, K. (2004). The discriminative power of the interval shuttle run test and the maximal multistage shuttle run test for playing level of soccer. Journal of Sports Medicine and Physical Fitness, 233 239.

Lewine, B.D., Gunderson, S.J. (1992). Altitude training does not improve running performance more than equivalent training near sea level in trained runners. Medicine Science in Sports and Exercise, May, Vol 24, No:5, s.569.

Little, J.P., Adeel, S., Safdar, G.P., Wilkin, M.A., Tarnopolsky and Martin, J.G., (2009). A practical model of low-volume high-intensity interval training induces mitochondrial biogenesis in human skeletal muscle: potential mechaniss. Journal of Physiology 588 (6): 1011-22. 
Altınkök, M. (2015). An analysis on the spheres of influence of high-intensity interval training (HIIT) practices. International Journal of Social Sciences and Education Research, 1 (2), 463-475.

Mc Manus, A. (1993). The effect of two differend training programs on the peak VO2 of prepubescent girls. Medicine Science in Sports and Exercise, 26(5):83.

Mc Manus, A.M., Cheng, C.H., Leung, M.P., Yung, T.C., Macfarlane, D.J. (2005). Improving aerobic power in primary school boys: a comparison of continuous and interval training. Int $J$ Sports Med, 26 (9), 781-6.

Morris, N., Gass, G., Thompson, M., Bennett, G., Basic, D., Morton, H. (2002). Rate and amplitude of adaptation to intermittent and continuous exercise in older men. Medicine and Science in Sports Exercise, 34 (3), 471-7.

Muratlı, S. (2007). Antrenman bilimi yaklaşımıyla çocuk ve spor. Nobel Yayın Dağıtım, Geliştirilmiş ve Düzeltilmiş 2. Baskı, Ankara.

Overend, T.J., Paterson, D.H., Cunningham, D.A. (1992). The effect of interval and continuous training on the aerobic parameters. Can J Sport Sci, 17(2),129-34.

Patlar, S., Sanioğlu, A., Kaplan, T. \& Polat, Y. (2003). Futbolcularda sürekli koşular metodu ile oyun formu metodunun dayanıklılık parametreleri üzerine etkisi. SÜ Beden Eğitimi ve Spor Bilim Dergisi, 5 (1-2): 10-17.

Reilly, T., (2000). Anthropometric and physiological predispositions for elite soccer. Journal of Sport Sciences, 669-683.

Revan, S., Balcı, S..S., Pepe, H. ve Aydoğmuş, M., (2008). Sürekli ve internal koşu antrenmanlarının vücut kompozisyonu ve aerobik kapasite üzerine etkileri. Spormetre Beden Eğitimi ve Spor Bilimleri Dergisi, C:6, S:4, ss:193-197.

Ribeiro Braga, L., De Mello, M.A., Gobatto, C.A. (2004). Continuous and intermittent exercise: effects of training and detraining on body fat in obese rats. Arch Latinoam Nutr, 54 (1), 58-65.

Savaş, S. (2000). Deniz seviyesi ile yükseltide uygulanan dayanıklılık antrenmanlarının bazı fizyolojik parametrelere olan etkilerinin tespiti ve üç hafta sonra tekrarlanan ölçüm değerleri ile karşılaştırılması. G.Ü. Kastamonu Ĕgitim Dergisi, Mart, Cilt:8, No:1, s.207-216.

Sevim, Y. (2002). Antrenman bilgisi, Nobel Yayın Dağıtım, Ankara, ss 65-72.

Tabata, I., Nishimura, K., Kouzaki, M., (1996). Effects of moderate-intensity endurance and high-intensity intermittent training on anaerobic capacity and VO2max. Medicine and Science in Sports Exercise, 28 (10): 1327-30.

Taş, M., Zorba, E. (2010). Sıcak ortamda yapılan farklı antrenman metotlarının glutatyon (gsh) ve malondialdehit (mda) düzeylerine etkisinin karşılaştırılması. Atabesbd, 12 (3), 1-8.

Trapp, E.G,, Chisholm, D.J., Freund, J. \& Boutcher, S.H. (2008). The effects of high-1ntensity intermittent exercise training on fat loss and fasting insulin levels of young women. International Journal of Obesity, 32: 684-691.

Williams, C.A. (1993). Effects of continous and interval training on anaerobic performances in prepubescent girls. Medicine Science in Sports and Exercise, 25(5):22, 417.

Yüksel, O., Koç, H., Özdilek, Ç., Gökdemir, K. (2007). Sürekli ve interval antrenman programlarının üniversite öğrencilerinin aerobik ve anaerobik gücüne etkisi. Sağllk Bilimleri Dergisi (Journal of Health Sciences), 16(3), 133-139. 
Altınkök, M. (2015). Yüksek şiddetli interval antrenman uygulamalarının etki alanlarının incelenmesi. International Journal of Social Sciences and Education Research, 1 (2), 463-475.

\section{Extended abstract in English}

Along with the technological changes and advancements in recent years, quite rapid changes and developments have been observed in the field of science, technology and communication, and such changes have affected sports activities and sports sciences either directly or indirectly as well as showing their effects on the social lives and performances of athletes (Günay, 1996, Altın ve Kaya 2012). The importance of physical exercises practised regularly each day is becoming more prominent in terms of health. It is reported that exercises enable the respiratory, digestive, excretory and musculoskeletal systems to be kept at desired levels as well as allowing the muscles, bones, joints, cardiovascular system and their functions to operate in an optimum fashion. While the central nervous system controls life dynamism, the heart regularly pumps blood throughout the human body throughout the lifetime. The coronary artery disease (CAD), hypertension and diabetes in those performing endurance sports (long distance races and swimming, cycling, etc.) are rarely seen (Akgün, 1973, Erkan, 1998).

The fact that training increase the maximal performance capacity is a commonly known fact (Fox, 1988). Adaptation to training is the sum of changes that emerge through repeating the exercises in a systematic way (Bompa, 2003). Since it is considered that the training methods applied on the youth will pave the way for their prospective sports lives, it is reported that they, in this respect, should be different from the training methods applied on adults. Inasmuch as children are not regarded as a miniature model of adults, it is argued that the training program to be applied on children needs to be the one that applies to child organism (Muratl1, 2007).

A number of studies have shown that high-intensity interval training performed adequately for at least several weeks increased oxygen intake and mitochondrial enzyme activities generating energy in the skeletal muscles (Gibala, 2007, http, 1). These structural and physiological changes in human organism are the outcomes of loading processes performed through a different and special training program practised by depending on the scope, intensity and frequency of the training at issue (Bompa, 2003). In line with this, one of the most effective and efficient types of training used for boosting performance and facilitating success in sports sciences and in different sports branches is reported to be the high-intensity interval training model (HIIT).

Interval training is the repetition of several series of exercises at certain intervals. The feature of interval training is revealed as a systematic change of training and relaxing or high and low loading stages (Revan ve ark., 2008). The characteristic feature of interval training is the systematic change of practice and resting or high and low loading cycles/periods (Sevim, 2002). The basic principle in interval training is that loading process is ceased when the number of heart beats during loadings have reached the maximal level, and a reloading is done after the number of heart beats has dropped down to the level of 120 beats/min in between repetitions and 140 beats $/ \mathrm{min}$ in between sets. The loading intensity in interval training is $80-90 \%$ (Fox ve ark., 1999).

Letzelter (1978) recommends 3-50 minute-recovery/resilience in intensive interval methods in order to develop explosive power. This is clearly opposed on the boundaries of the continuous training method (http, 2). Astrand and Rodahl (1987), on the other hand, researched into the efficiency of loading and resting periods during interval training and reported as the result of their research that 1:1 (one-to-one) resting/relaxing period was appropriate. Several researches determined the short interval training as 15 seconds- 2 minutes, the moderate interval training as 2-8 minutes and the long interval training as 8-15 minutes. In this specification, the variety of stimuli depending on 
Altınkök, M. (2015). An analysis on the spheres of influence of high-intensity interval training (HIIT) practices.

International Journal of Social Sciences and Education Research, 1 (2), 463-475.

the systematic changes between the effort and recovery performed during the intermittent/interval training was ignored (http, 2). The basic principle in interval training is to stop the practice when the number of heart beats reaches up to 180-200 and then to continue practising when the number of heart beats drops down to 120-130. The general principles to be taken into consideration can be listed as the duration of practice, its scope, intensity and recovery/resting (http, 3).

Peter Coe' Type-High-Intensity Interval Training: This is the method applied in 1970 by an athletic trainer/coach, Peter Coe. In this method, the sessions consist of a 200 meter-departure/start and a 30-second-relaxation period at each 200 meters (Coe, 2013).

Tabata' Type-High-Intensity Interval Training: This is the type of a high-intensity interval training based on a study conducted by Izumi Tabata et al. in 1996. It was performed by Olympic speed skaters. In this method, a 20-second-ultra-intensive exercise (roughly 170\% VO2max) is performed, and following this, a 10-second-recovery/relaxation period is given. 8 cycles for 4 minutes is continuously performed (Tabata ve ark., 1996).

Gibala Type-High-Intensity Interval Training: This method used in the high-intensity interval training practices of Martin Gibala et al. in 2009 in Canada Mc Master University, Canada consists of a 3-minute-warming up, a 60-second-intensive training (95\% VO2max), and following this, a 75second-recovery/relaxation period along with an 8-12 repetitive cycles (Little ve ark., 1996).

Timmon' Type- High- Intensity Interval Training: This is the method which Jamie Timmons had Michael J. Mosley apply in the program called "Horizon", which they participated in on the BBC channel in February, 2012; this method consists of a 2-minute pedaling on the exercise bike and a 20minute-accelaration/speeding up stage with the highest effort after that. It was practised 3 times for 3 minutes a week along with the warming up and relaxation stages. As for the assessable advantages of this program on health, a remarkable development in insulin susceptibility was reported (http, 5).

High-intensity interval training enable aerobic and anaerobic energy systems to be used more effectively. In the conducted studies, it was stated that these trainings had increased oxygen intake and mitochondrial enzyme activities that generate energy in the skeletal muscles. Hence, the endurance capacity is increased by renewing the anaerobic energy resources consumed in this way through the use of aerobic energy resources.

In conclusion, the conducted studies suggest that high-intensity interval training practices have yielded successful results. Apart from this, it is seen that the results have been affected on different levels due to the type, duration and intensity of the practised training programs as well as the type of subjects/trials, the periods during which pre-program and post-program measurements were performed, the difference among the applied methods and the different environment the research was conducted in. 